\title{
Erros nas prescrições medicamentosas odontológicas: um estudo transversal em
}

\section{drogarias}

\author{
Errors in dental drug prescriptions: a cross-sectional study in drugstores \\ Errores en la prescripción de medicamentos dentales: un estudio transversal en farmacias
}

Recebido: 29/10/2021 | Revisado: 09/11/2021 | Aceito: 22/11/2021 | Publicado: 01/12/2021

Bárbara Maris Caliari

ORCID: https://orcid.org/0000-0002-9628-6204 Faculdade Patos de Minas, Brasil E-mail: barbara.08477@alunofpm.com.br

Fernanda Souza Rosa

ORCID: https://orcid.org/0000-0001-9120-2027 Faculdade Patos de Minas, Brasil E-mail: fernanda.07449@alunofpm.com.br

Ana Cláudia de Souza

ORCID: https://orcid.org/0000-0002-2947-9364 Centro Universitário de Brasília, Brasil

E-mail: ana.claudia@ceub.com.br

Victor da Mota Martins

ORCID: https://orcid.org/0000-0001-6631-6161

Centro Universitário de Patos de Minas, Brasil

E-mail: victortag@hotmail.com

Luiza Ribeiro Caliari

ORCID: https://orcid.org/0000-0002-1121-371X

Centro Universitário de Patos de Minas, Brasil E-mail: lucaliarifoto@gmail.com

Luana Ribeiro Caliari

ORCID: https://orcid.org/0000-0003-3217-6273

Centro Universitário de Patos de Minas, Brasil E-mail: luanacaliari@hotmail.com

Guilherme Rabelo de Souza

ORCID: https://orcid.org/0000-0002-0834-6415 Universidade Federal de Alfenas, Brasil

E-mail: guisouzarabelo@gmail.com

\begin{abstract}
Resumo
Prescrições medicamentosas odontológicas visam cura ou alívio de situações clínicas importantes como infecções, inflamação, dor, ansiedade, entre outras. Entretanto, erros em prescrições medicamentosas são rotineiros, fato este que inviabiliza a dispensação do fármaco e prejudica o tratamento. O presente trabalho teve como objetivo avaliar o conhecimento dos cirurgiões-dentistas para a realização de prescrições de medicamentos pertencentes à classe de antimicrobianos, sendo esses associados ou não a outras classes farmacológicas. As prescrições foram analisadas no período de 10/05/2021 a 30/07/2021, no momento da venda e da dispensação dos medicamentos. As prescrições farmacológicas que estavam de acordo com a Resolução RDC No 471 de 23 de fevereiro de 2021 permitiram a venda e dispensação dos medicamentos pelas drogarias e os receituários foram retidos e arquivados (1a via do receituário) no estabelecimento farmacêutico. As prescrições incorretas impossibilitaram a venda e dispensação dos medicamentos e dessa forma foram devolvidas ao prescritor. Foram analisadas 207 prescrições odontológicas, sendo que 31,4\% apresentavam algum erro no documento. O erro mais prevalente foi relacionado à posologia dos fármacos, representando o total de $79,14 \%$ de todos os erros encontrados nas prescrições. Além dos antimicrobianos, também encontramos outras classes de medicamentos nas prescrições, como anti-inflamatórios, analgésicos, antifibrinolíticos, antissépticos e antifúngicos. O presente trabalho ressalta a importância do conhecimento farmacológico e da legislação vigente para a realização de prescrições farmacológicas que permitam a venda e dispensação dos medicamentos para os pacientes.
\end{abstract}

Palavras-chave: Antimicrobianos; Prescrições; Medicamentos.

\begin{abstract}
Dental drug prescriptions aim to cure or alleviate important clinical situations such as infections, inflammation, pain, anxiety, among others. However, errors in drug prescriptions are routine, a fact that makes dispensing the drug unfeasible and impairs the treatment. The present study aimed to evaluate the knowledge of dentists to carry out prescriptions for drugs belonging to the class of antimicrobials, associated or not with other medicines. Prescriptions
\end{abstract}


were analyzed from $05 / 10 / 2021$ to $07 / 30 / 2021$ at the time of sale and dispensing of the drugs. The pharmacological prescriptions that were in accordance with Resolution RDC No. 471 of February 23, 2021, allowed the sale and dispensing of medicines by drugstores and the prescriptions were retained and filed (1st copy of the prescription) at the pharmaceutical establishment. Incorrect prescriptions made it impossible to sell and dispense the drugs and, therefore, they were returned to the prescriber. A total of 207 dental prescriptions were analyzed, and $31.4 \%$ of the prescriptions had some error in the document. The most prevalent error was related to drug dosage, representing a total of $79.14 \%$ of all errors found in prescriptions. In addition to antimicrobials, we also find other classes of medications in drug prescriptions such as anti-inflammatories, analgesics, antifibrinolytics, antiseptics and antifungals. The present work emphasizes the importance of pharmacological knowledge and current legislation for the realization of pharmacological prescriptions that allow the sale and dispensing of medicines to the patients.

Keywords: Antimicrobials; Prescriptions; Medicines.

\begin{abstract}
Resumen
Las recetas de medicamentos dentales tienen como objetivo curar o aliviar situaciones clínicas importantes como infecciones, inflamación, dolor, ansiedad, entre otras. Sin embargo, los errores en la prescripción de medicamentos son rutinarios, hecho que hace inviable la dispensación del medicamento y perjudica el tratamiento. El presente estudio tuvo como objetivo evaluar los conocimientos de los odontólogos para realizar prescripciones de fármacos pertenecientes a la clase de antimicrobianos, asociados o no a otras clases farmacológicas. Las prescripciones se analizaron desde el 10/05/2021 hasta el 30/07/2021 en el momento de la venta y dispensación de los medicamentos. Las prescripciones farmacológicas que cumplieron con la Resolución RDC No. 471 del 23 de febrero de 2021, permitieron la venta y dispensación de medicamentos por las farmacias y las prescripciones fueron retenidas $\mathrm{y}$ archivadas ( $1^{\mathrm{a}}$ copia de la prescripción) en el establecimiento farmacéutico. Las prescripciones incorrectas hicieron imposible vender y dispensar los medicamentos y, por lo tanto, fueron devueltos al prescriptor. Se analizaron un total de 207 recetas dentales y el 31,4\% de las recetas tenían algún error en el documento. El error más prevalente estuvo relacionado con la dosificación del fármaco, representando un total del 79,14\% de todos los errores encontrados en las prescripciones. Además de los antibióticos, también encontramos otras clases de medicamentos en la prescripción como antiinflamatorios, analgésicos, antifibrinolíticos, antisépticos y antifúngicos. El presente trabajo enfatiza la importancia del conocimiento farmacológico y la legislación vigente para la realización de prescripciones farmacológicas, que permitan la dispensación de medicamentos a los pacientes.
\end{abstract}

Palabras clave: Antimicrobianos; Prescripción; Medicamentos.

\title{
1. Introdução
}

O cirurgião-dentista depara-se com diversas patologias na cavidade oral, sendo necessário intervenções odontológicas, almejando o restabelecimento fisiológico. Para favorecer o tratamento odontológico, muitas vezes o cirurgião dentista necessita prescrever medicamentos para eliminar infecções, reduzir inflamação, dor, febre e até mesmo crise aguda de ansiedade, ocasionados pelo medo ou trama de experiências passadas em consultórios odontológicos (Castilho, Paixão, \& Perini, 1999).

A prescrição de medicamentos pelos cirurgiões-dentistas é garantida pela lei $\mathrm{n}^{\mathrm{o}} 5.081$ de 24 de agosto de 1966 , no artigo 6 e estabelece, no inciso II, que - "cirurgiões-dentistas podem prescrever e aplicar especialidades farmacêuticas de uso interno e externo, indicadas em odontologia”. Já no inciso VIII as prescrições farmacológicas são também permitidas em casos de urgência, como em acidentes graves que comprometam a vida e a saúde do paciente" (Brasil, 1966). Em relação aos medicamentos sujeitos a controle especial, como psicotrópicos, a Portaria SVS/MS n 344 , de 12 de maio de 1998 , regula no artigo 38 que as prescrições farmacológicas realizadas por cirurgiões dentistas devem ser singulares para uso odontológico (Brasil, 1998; Falcão, 2014).

As classes farmacológicas mais comumente empregadas na rotina odontológica são os antimicrobianos, antiinflamatórios e analgésicos. A introdução do antibiótico penicilina na década de 1940 constitui um dos avanços mais importantes na história da medicina, proporcionando naquela época tratamento farmacológico contra microrganismos invasores, contribuindo dessa forma para a redução na mortalidade. Na atualidade, diversos antimicrobianos estão disponíveis e diferenciam-se pela estrutura química e pelo mecanismo de ação. Normalmente os antimicrobianos são tóxicos aos microrganismos invasores, porém apresentam pouca toxicidade para os pacientes e são amplamente prescritos por cirurgiõesdentistas (Guimarães, Momesso, \& Pupo, 2010). Os fármacos anti-inflamatórios são divididos em anti-inflamatórios não 
esteroidais (AINEs) e anti-inflamatórios esteroidais (AIEs), sendo ambos utilizados para reduzirem o processo inflamatório e, por consequência, promovem analgesia (Andrade, 2014). Os analgésicos são fármacos utilizados para o alívio da dor de intensidades variadas e são divididos em opióides e não opióides (Flores, Castro, \& Nascimento, 2012). Embora os analgésicos apresentem mecanismos de ação distintos, o objetivo do tratamento farmacológico é único: induzir analgesia, reduzindo dessa forma a sensação de dor nos pacientes.

Conforme Busanello et al. (2017) a Resolução nº 357, de 20 de abril de 2001doConselho Federal de Farmácia (CFF), no artigo 21, define que o estabelecimento farmacêutico só poderá dispensar os medicamentos prescritos por profissional apto se:

I) estiver escrito à tinta, em português, em letra de forma clara e legível, observada a nomenclatura oficial dos medicamentos e o sistema de pesos e medidas oficiais do Brasil. A datilografia ou impressão por computador é aceitável; II) contiver o nome e o endereço residencial do paciente; III) contiver a forma farmacêutica, posologia, apresentação, método de administração e duração do tratamento; IV) contiver a data e a assinatura do profissional, endereço do consultório e o número de inscrição no respectivo conselho profissional. A prescrição deve ser assinada claramente e acompanhada do carimbo, permitindo identificar o profissional, em caso de necessidade. V) a prescrição não deve conter rasuras e emendas (CFC, 2001).

Embora a Resolução anteriormente descrita seja clara, erros nas prescrições farmacológicas são constantes, ocasionando dessa forma administração incorreta, trocas de medicamentos, alterações na posologia, reduzindo o sucesso da terapia medicamentosa (Brasil, 2013, Jacobsen, Mussi, \& Silveira, 2019; Lima et al., 2016b). As situações que podem levar aos erros nas prescrições de medicamentos são diversas e as mais comuns são: deficiências na formação acadêmica, uso de fontes de pesquisa desatualizadas e/ou incorretas e falta de conhecimento da legislação vigente (Cassiani, Monzani, \& Silva, 2010; Garbin, Garbin, Rovida, Moroso, \& Dossi, 2007). Assim, para evitar erros nas prescrições medicamentosas que possam inviabilizar a dispensação do fármaco, o cirurgião-dentista deve possuir conhecimentos atualizados de farmacologia e das normas vigentes sobre prescrições e dispensação de medicamentos pelo estabelecimento farmacêutico, de forma a evitar erros que prejudiquem ou até mesmo inviabilizem a dispensação e o tratamento farmacológico do paciente. Diante da problemática acima relatada, o objetivo do presente trabalho foi quantificar erros em prescrições farmacológicas odontológicas e identificar os erros mais encontrados.

\section{Metodologia}

O presente trabalho foi realizado através de estudo transversal. Foram analisadas prescrições farmacológicas odontológicas em duas drogarias privadas na cidade de Patos de Minas - MG. A amostra foi composta pelas prescrições de antimicrobianos associados ou não a outras classes farmacológicas (na mesma prescrição medicamentosa; co-prescrição), provenientes de cirurgiões-dentistas. As prescrições foram recebidas e avaliadas pelos responsáveis técnicos (farmacêuticos) antes da dispensação dos medicamentos. A amostra foi composta por 80 prescrições recebidas na primeira drogaria participante do trabalho e 127 recebidas na segunda drogaria, totalizando 207 prescrições farmacológicas. A coleta dos dados foi realizada no período entre 10/05/2021 a 30/07/2021, no momento da venda dos medicamentos pelos estabelecimentos farmacêuticos.

Para atender a Resolução RDC no 471, de 23 de fevereiro de 2021, todas as prescrições farmacológicas foram analisadas como corretas ou incorretas antes de os medicamentos serem dispensados aos pacientes. Os itens analisados foram: escrita legível; presença de rasuras; nome do princípio ativo do medicamento; forma farmacêutica; posologia completa e correta (dose do medicamento, via de administração, intervalo entre as administrações e a duração do tratamento); nome completo do paciente; assinatura do profissional; número de inscrição no Conselho; carimbo do profissional e dados da clínica 
odontológica. As prescrições que apresentavam erros nos itens acima mencionados inviabilizaram a dispensação dos medicamentos, e as prescrições foram devolvidas aos prescritores. Os dados foram coletados pelos farmacêuticos das drogarias e repassados aos pesquisadores para inserção na planilha do programa Microsoft Office Excel 2007. Para a realização dos gráficos foi utilizado o software GraphPad Prism versão 7.0. Os resultados são apresentados na forma de tabelas e gráficos, utilizando a frequência absoluta e a frequência relativa. O projeto de pesquisa foi aprovado pelo Comitê de Ética em Pesquisa envolvendo Seres Humanos da Faculdade Patos de Minas (CAAE 45489221.4.0000.8078).

\section{Resultados}

Avaliações de prescrições medicamentosas são rotina em farmácias e drogarias e é crucial para permitir a dispensação dos fármacos prescritos por profissionais habilitados. Dessa forma, as 207 prescrições medicamentosas de antimicrobianos prescritas por cirurgiões-dentistas, (com ou sem co-prescrição) foram avaliadas antes da dispensação farmacêutica, e revelouse o total de 65 prescrições com algum tipo de erro, correspondendo a 31,4\%, fato este que inviabilizou a terapia farmacológica. Os erros foram contabilizados nessas 65 prescrições e o total de 163 erros foram encontrados, apresentando uma média de aproximadamente 2,5 erros por prescrição medicamentosa (figura 1B). Do total dos erros encontrados, 129 foram relacionados à posologia $(79,14 \%)$. Os demais foram referentes à ausência de dados da clínica (21 prescrições; 12,9\%), ausência de carimbo do prescritor (6 prescrições; 3,68\%), ausência de dados do paciente (4 prescrições; 2,45\%) e ausência de assinatura do prescritor (3 prescrições; 1,84\%) (Figura 1B).

Após a análise das prescrições como corretas ou incorretas, 207 prescrições foram analisadas para identificar qual antimicrobiano foi mais prescrito pelos cirurgiões dentistas. Dentre os antimicrobianos, a amoxicilina foi o fármaco mais prescrito pelos cirurgiões-dentistas, perfazendo $58,45 \%$ de todas as prescrições. Os demais antimicrobianos encontrados nas prescrições medicamentosas foram a azitromicina $(24,15 \%)$, amoxicilina associada ao clavulanato $(9,18 \%)$ e metronidazol $(5,80 \%)$ (Tabela 1$)$.

Além dos antimicrobianos, algumas das prescrições farmacológicas apresentaram outras classes farmacológicas associadas (co-prescrição), como por exemplo os AINEs, analgésicos, AIEs, antifúngicos entre outros (Tabela 2). Após análise das prescrições, foi verificado que os AINEs foram os medicamentos mais prevalentes na co-prescrição dos antimicrobianos. Os medicamentos mais prescritos foram nimesulida (25,14\%), ibuprofeno $(13,97 \%)$ e diclofenaco $(2,79 \%)$. As prescrições farmacológicas de analgésicos não opióides ocupou o segundo lugar na prevalência de co-prescrições dos antimicrobianos e mostrou ser a dipirona (20,11\%) principal escolha para alívio da dor. Em relação à prescrição de AIEs, foi verificado que a dexametasona obteve o maior número de co-prescrições, perfazendo o total de $6,14 \%$. Os opióides ocuparam a quarta posição na prevalência de medicamentos co-prescritos dos antimicrobianos e a escolha na prescrição dos cirurgiões-dentistas foi codeína associada ao paracetamol (5,59\%). Outros fármacos co-prescritos por cirurgiões-dentistas, entretanto em menor número, são mostrados na Tabela 3. 
Figura 1 - Erros em prescrições odontológicas.
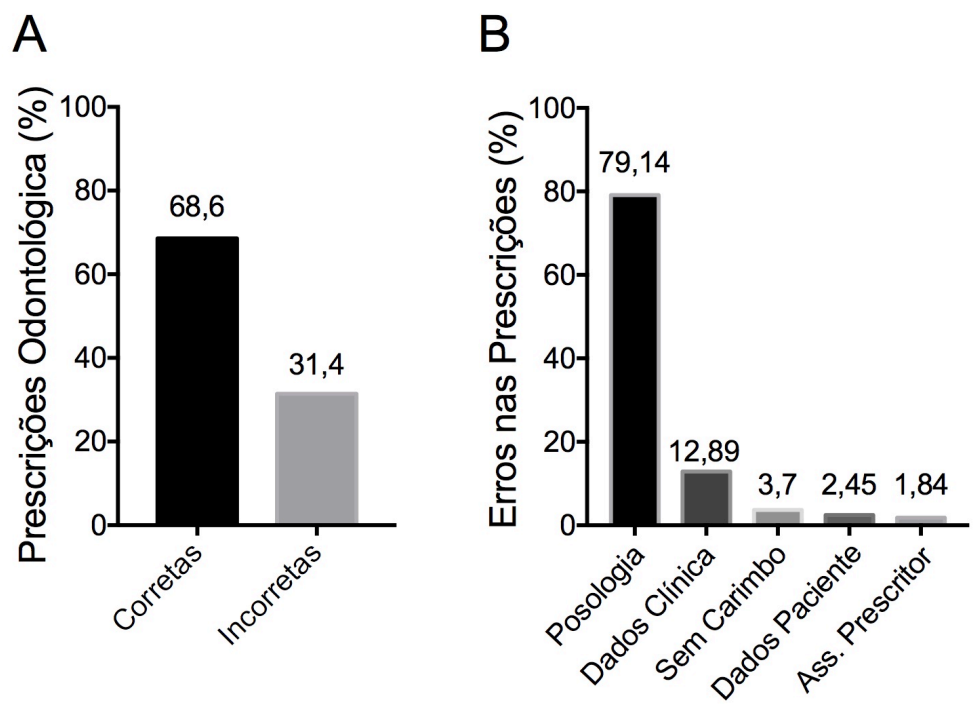

Figura 1) Análise de erros em prescrições farmacológicas odontológicas. Identificação das prescrições medicamentosas como corretas ou incorretas (figura 1A). Identificação dos erros encontrados nas prescrições farmacológicas (figura 1B). Os dados foram expressos pela frequência relativa.

Fonte: Autores.

Tabela 1 - Medicamentos prescritos pelos Cirurgiões-dentistas.

\begin{tabular}{lcc}
\hline $\begin{array}{l}\text { Medicamentos } \\
\text { Prescritos }\end{array}$ & $\begin{array}{c}\text { Frequência } \\
\text { Absoluta (n) }\end{array}$ & $\begin{array}{c}\text { Frequência } \\
\text { Relativa (\%) }\end{array}$ \\
\hline Antibióticos & & \\
Amoxicilina & 121 & $58,45 \%$ \\
Azitromicina & 50 & $24,15 \%$ \\
Amoxicilina + clavulanato & 19 & $9,18 \%$ \\
de potássio & & $5,80 \%$ \\
Metronidazol & 12 & $1,45 \%$ \\
Lefalexina & 3 & $0,9 \%$ \\
\hline
\end{tabular}

Fonte: Autores. 
Tabela 2 - Classes Farmacológicas prescritas pelos Cirurgiões-dentistas.

\begin{tabular}{lcc}
\hline Classes Farmacológicas & $\begin{array}{c}\text { Frequência } \\
\text { Absoluta (n) }\end{array}$ & $\begin{array}{c}\text { Frequência } \\
\text { Relativa (\%) }\end{array}$ \\
\hline AINEs & 85 & $47,49 \%$ \\
Analgésicos não opióides & 55 & $30,73 \%$ \\
AIEs & 13 & $7,26 \%$ \\
Analgésicos opióides & 12 & $6,70 \%$ \\
Antissépticos & 9 & $5,03 \%$ \\
Antifúngicos & 3 & $1,67 \%$ \\
Antifibrinolíticos & 2 & $1,12 \%$ \\
\hline
\end{tabular}

Fonte: Autores. 
Tabela 3 - Medicamentos prescritos pelos Cirurgiões-dentistas.

$\begin{array}{ccc}\text { Medicamentos Prescritos } & \begin{array}{c}\text { Frequência } \\ \text { Absoluta (n) }\end{array} & \begin{array}{c}\text { Frequência } \\ \text { Relativa (\%) }\end{array}\end{array}$

AINEs

Nimesulida

45

$25,15 \%$

Ibuprofeno

25

$13,97 \%$

Diclofenaco

$2,79 \%$

Trometamol cetorolaco

$1,67 \%$

Piroxicam

Cetoprofeno

Celecoxibe

$1,67 \%$

$1,12 \%$

$1,12 \%$

Analgésicos não opióides

Dipirona

36

$20,11 \%$

Paracetamol

12

$6,70 \%$

Dipirona + Cloridrato de prometazina

$3,91 \%$

+ Cloridrato de adifenina

AIEs

Dexametasona

11

$6,14 \%$

Prednisona

2

$1,12 \%$

Analgésicos opióides

Paracetamol + Codeína

$10 \quad 5,59 \%$

Codeína

$2 \quad 1,12 \%$

Antisséptico

Clorexidina $0,12 \%$

9

$5,03 \%$

Antifúngico

Nistatina

3

$1,67 \%$

Antifibrinolítico

Ácido tranexâmico

$2 \quad 1,12 \%$

Fonte: Autores. 


\section{Discussão}

Os resultados obtidos no presente trabalho corroboram os dados da literatura e sugerem que erros em prescrições odontológicas são comuns, porém desfavorecem o tratamento farmacológico prescrito pelos cirurgiões dentistas, pois inviabilizam a dispensação dos medicamentos pelas farmácias ou drogarias (Araújo, Biagini, Fernandes, Caputo, \& Silva, 2012; Catarino et al., 2021; Souza, Silva, \& Brito, 2011). Os resultados demonstraram 31,4\% de erros nas prescrições realizadas pelos cirurgiões-dentistas. Também foi constatado que as prescrições medicamentosas apresentavam mais de um medicamento na mesma receita (co-prescrição). Dessa forma, poderiam ser encontrados mais de um erro nas prescrições analisadas. De fato, foi encontrado uma média aproximada de 2,5 erros nas prescrições odontológicas, sugerindo assim que quanto maior o número de medicamentos na mesma prescrição, maior é a possibilidade de erros. O trabalho avaliou também qual seria a maior prevalência dos tipos de erros nas prescrições odontológicas. Surpreendentemente quase 80\% de todos os erros encontrados nas prescrições estavam relacionados à posologia do medicamento prescrito. Os erros de posologia foram relacionados à dose do medicamento, via de administração, intervalo entre as administrações e duração do tratamento. O conhecimento sobre o fármaco a ser prescrito pelo cirurgião-dentista é fundamental para se evitar erros (Araújo et al., 2012). Corroborando estes resultados, Lisboa (2015) encontraram similaridade, mostrando erros no intervalo e duração do tratamento farmacológico. Ainda Lins, Cazzamalli e Zancanaro (2012) constataram que os erros estavam relacionados à ausência da via de administração dos fármacos prescritos. Dessa forma, podemos inferir que o conhecimento farmacológico e da legislação vigente é de grande importância para a realização de prescrições medicamentosas corretas.

As prescrições medicamentosas em odontologia visam à cura ou alívio das situações que acometem o paciente como: infecções, inflamação, dor, ansiedade, dentre outras. As infecções de importância odontológica mais relevantes são ocasionadas principalmente pelos microrganismos anaeróbios obrigatórios e que causam infecção dento alveolar, cárie dentária, infecções pós cirúrgicas e pericoronarite, respectivamente (Costa, 2018). Dessa forma, o uso de antimicrobianos é preconizado na clínica odontológica para tratamento das infecções agudas e/ou crônicas, profilática em pacientes de risco para desenvolvimento de endocardite bacteriana e profilática para pacientes com algum grau de comprometimento do sistema imune (Barreto \& Pereira, 2008). A primeira escolha para tratamento de infecções bacterianas na cavidade oral é a amoxicilina, pois as bactérias gram-positivas aeróbias são normalmente sensíveis ao tratamento com esse medicamento (Melo, Duarte e Soares, 2012). Os resultados aqui encontrados confirmam os dados da literatura, visto ter sido a amoxicilina a primeira escolha dos cirurgiões-dentistas para prescrever antimicrobianos. Entretanto, um problema de extrema importância é a resistência bacteriana relacionada ao uso indiscriminado de antimicrobianos. Sendo assim, embora o presente trabalho não tenha dado subsídios necessários para sugerir uso indevido de antimicrobianos, alerta sobre uma reflexão relativa à necessidade da prescrição desses medicamentos, visto ser a resistência bacteriana uma atualidade muito desfavorável aos clínicos de todo o mundo (Loureiro, Roque, Rodrigues, Herdeiro, \& Ramalheira, 2016).

Em alguns casos de infecção bacteriana na cavidade oral, os sinais cardinais do processo inflamatório são facilmente identificados e, sem dúvida, a dor é o que gera mais incômodo (Costa, Ribeiro, \& Cabral, 2012). Dessa forma, além do tratamento farmacológico com antimicrobianos, é necessário a prescrição de medicamentos para reduzir o processo inflamatório, a dor e a febre dos pacientes (Brasil, 2012). Sendo assim, também foram verificadas outras classes de medicamentos prescritas em conjunto com antimicrobianos. Os AINEs foram os medicamentos prescritos com maior intensidade. Essa associação justifica-se, pois na grande maioria dos casos de infecção observa-se inflamação e com muita frequência ocorre a sensibilização dos neurônios sensitivos, proporcionando edema e dor, respectivamente (Catterall \& Mackie, 2019). Em alguns casos o patógeno promove a liberação de pirógenos que alteram o limiar de disparo de neurônios hipotalâmicos, proporcionando febre. Dessa forma, os AINEs também podem ser utilizados para a redução da temperatura corporal (Whalen, Finkel, \& Panavelil, 2016). Embora os AINEs sejam medicamentos utilizados com rotina na clínica 
odontológica, seu uso prolongado pode induzir reações adversas como lesão no trato gastrointestinal, insuficiência renal aguda e insuficiência cardíaca. Portanto, a prescrição desses medicamentos deve ser cautelosa (Moore, Derry, \& McQuay, 2007).

Prescrições de AIEs associados aos antimicrobianos também foram encontradas no presente trabalho, entretanto, a prevalência foi menor. Esses são fármacos potentes para se reduzir o processo inflamatório e vêm sendo utilizados com frequência em situações odontológicas pré-operatórias (Boonsiriseth, Klongnoi, Sirintawat, Saengsirinavin, \& Wongsirichat, 2012). Embora sua potência anti-inflamatória seja almejada na clínica médica e odontológica, seus efeitos adversos devem ser considerados, principalmente se o tratamento farmacológico for crônico. As reações adversas dos AIEs são distúrbios líquidos e eletrolíticos, musculares, gastrintestinais, dermatológicos, psiquiátricos, endócrinos, imunológicos, entre outros (Vicente, Loffi, \& Nesi, 2013).

Em casos de dor moderada à intensa na clínica odontológica, a prescrição de analgésicos se faz necessária. Os analgésicos não opióides e os opióides mais prescritos no presente trabalho foram a dipirona e a associação entre o paracetamol e codeína, respectivamente. Os resultados aqui encontrados reforçam os dados da literatura onde a co-prescrição de antimicrobianos, anti-inflamatórios e analgésicos pode ser realizada, objetivando a redução da infecção, da inflamação e da dor (Lima et al., 2016a; Marmitt, 2010; Walter, 2019). É importante mencionar que a associação de fármacos com diferentes mecanismos de ação é plausível, podendo favorecer melhora clínica, entretanto quanto maior o número de fármacos administrados, maior é a possibilidade de interações medicamentosas. Assim, associações farmacológicas devem ser realizadas com cautela (Secoli, 2001).

Os antifúngicos, antissépticos e antifibrinolíticos também são fármacos prescritos pelos cirurgiões-dentistas e prescrições desses fármacos também são encontradas no presente trabalho. Antifúngicos são indicados para o tratamento de doenças orais como a candidíase oral, blastomicose e estomatite protética e os medicamentos mais utilizados são a nistatina e o miconazol (Lima, 2013). Os antissépticos, por sua vez, são indicados por cirurgiões dentistas para o controle da placa bacteriana e antissepsia pré-cirúrgica, reduzindo dessa forma infecção cruzada e infecção pós-operatória (Araújo et al., 2015). Os antifibrinolíticos são fármacos prescritos pelos cirurgiões-dentistas para cirurgia oral em pacientes com coagulopatias, como método auxiliar na hemostasia (Milani et al., 2017).

\section{Conclusão}

O presente trabalho verificou que mais de $30 \%$ das prescrições medicamentosas realizadas por cirurgiões-dentistas continham erros, impossibilitando a venda e dispensação dos medicamentos pelos estabelecimentos farmacêuticos. Também foi verificado que a grande maioria dos erros encontrados estavam relacionados à posologia dos medicamentos, sugerindo falta de conhecimento farmacológico para realizar prescrições medicamentosas. Outros erros encontrados nas prescrições foram a ausência de dados da clínica, do paciente ou do prescritor, sugerindo falta de atenção do prescritor no momento da realização da prescrição medicamentosa.

Uma importante estratégia para reduzir os erros em prescrições medicamentosas é a realização de cursos de atualização, que poderão fortalecer os conhecimentos sobre terapias farmacológicas em odontologia e sobre as legislações vigentes, favorecendo, dessa forma, a redução de erros em prescrições, o que beneficiará o paciente odontológico.

Dessa forma, conclui-se que o conhecimento do cirurgião-dentista sobre os medicamentos e a legislação vigente são extremamente importantes para a realização da prescrição medicamentosa, pois a correta prescrição medicamentosa odontológica contribui para um tratamento seguro, eficaz e reduz o custo do tratamento. 


\section{Referências}

Andrade, E. D. (2014). Terapêutica medicamentosa em odontologia. (3a ed.). Artes Médicas.

Araújo, D. B., Campos, E. J., Martins, G. B., Araújo, M. T. B., Assis, M. S., Santos, T. S. et al. (2015). Estudo dos enxaguatórios bucais disponíveis nas drogarias, farmácias e supermercados na cidade do Salvador, BA. Revista Bahiana de Odontologia, 6(1), 14-33.

Araújo, L. G., Biagini, F. C., Fernandes, R. L., Caputo, I. G. C., \& Silva, R. H. A. (2012). Conhecimento de acadêmicos de Odontologia sobre os aspectos clínicos, éticos e legais da prescrição medicamentosa. Revista da Faculdade de Odontologia - UPF, 17(1), 50-54.

Barreto, R. C., \& Pereira, G. A. S. (2008). Farmacoterapia na clínica odontológica. Universitária.

Boonsiriseth, K., Klongnoi, B., Sirintawat, N., Saengsirinavin, C., \& Wongsirichat, N. (2012). Comparative study of the effect of dexamethasone injection and consumption in lower third molar surgery. Int. J. Oral Maxillofac. Surg., 41(2), 244-247.

Brasil. Câmara dos Deputados. (1966). Lei $n^{o}$ 5.081, de 24 de agosto de 1966: regula o exercício da Odontologia. https://www2.camara.leg.br/legin/fed/lei/1960-1969/lei-5081-24-agosto-1966-364652-normaatualizada-pl.pdf

Brasil. Ministério da Saúde. Secretaria de Ciência, Tecnologia e Insumos Estratégicos. Departamento de Assistência Farmacêutica e Insumos Estratégicos. Coordenação Geral de Assistência Farmacêutica e Insumos Estratégicos. (2012). Uso Racional de medicamentos. Brasília: Autor.

Brasil. Ministério da Saúde. Agência Nacional de Vigilância Sanitária. (2013). Resolução $n^{o} 36$ de 25 de julho de 2013 : institui ações para a segurança do paciente em serviços de saúde e dá outras providências. DOU.

Brasil. Ministério da Saúde. Secretaria de Vigilância em Saúde. (1998). Portaria $n^{\circ}$ 344, de 12 de maio de 1998: aprova o Regulamento Técnico sobre substâncias e medicamentos sujeitos a controle especial. DOU.

Busanello, C., Gomes, E., Galina, K. J., Junior, J. S. G., Provasi, M., Hashimoto, M. S. M. et al. (2017). Farmácia com manipulação: guia da profissão. (1a ed.). Curitiba: Conselho Regional de Farmácia do Paraná. http://www.crf-pr.org.br/uploads/pagina/28666/ jUk3grXdUY901sSM7Hko1sH3XFX03v1A.pdf

Cassiani, S. H. B., Monzani, A. A. S., \& Silva, A. E. B. C. (2010). Identificação e análise dos erros de medicação em seis hospitais brasileiros. Ciência e Enfermagem, 16(1),85-95.

Castilho, L. S., Paixão, H. H., \& Perini, E. (1999). Prescrição de medicamentos de uso sistêmico por cirurgiões-dentistas, clínicos gerais. Revista de Saúde Pública, 33(3), 287-294.

Catarino, K. F. F., Lorenzzi, S. C. S., Uzeda, M. J. P. G., Louro, R. S., Maia, M. D. C., Sá, J. C. R. et al. (2021). Como fazer uma correta prescrição medicamentosa e quais os importantes cuidados? Revista Fluminense de Odontologia, XXVII(55), 108-120.

Catterall, W. A., \& Mackie, K. (2019). Goodman \& Gilman: as bases farmacológicas da terapêutica. (13a ed.). McGraw-Hill.

Conselho Federal de Farmácia - CFC. (2001). Resolução $n^{\circ} 357$ de 20 de abril de 2001: aprova o regulamento técnico das Boas Práticas de Farmácia. Brasília: Autor. https://www.cff.org.br/userfiles/file/resolucoes/357.pdf

Costa, P. P. (2018). Infecção odontogênica: revisão de literatura e análise dos procedimentos realizados em um hospital público de Belo Horizonte, Minas Gerais - Brasil. Monografia de Especialização em Cirurgia e Traumatologia Buco-Maxilo-Facial, Universidade Federal de Belo Horizonte, Belo Horizonte.

Costa, R. S. M., Ribeiro, S. N., \& Cabral, E. D. (2012). Fatores determinantes de experiência dolorosa durante atendimento odontológico. Revista dor, 13(4), $365-70$.

Falcão, A. F. P. (2014). A relevância do atendimento às Normas de Regulamentação do Exercício Profissional. Revista de Ciências Médicas e Biológicas, $13(1), 3-6$.

Flores, M. P., Castro, A. P. C. R., \& Nascimento, J. S. (2012). Analgésicos tópicos. Revista Brasileira de Anestesiologia, 62(2), 244-252.

Garbin, C. A.S., Garbin, A. J. I., Rovida, T. A. S., Moroso, T. T.; \& Dossi, A. P. (2007). Conhecimento sobre prescrição medicamentosa entre alunos de odontologia: o que sabem os futuros profissionais? Revista odontológica UNESP, 36(4), 323-329.

Guimarães, D. O., Momesso, L. S., \& Pupo, M. T. (2010). Antibióticos: importância terapêutica e perspectivas para a descoberta e desenvolvimento de novos agentes. Química Nova, 33(3), 667-679.

Jacobsen, T. F., Mussi, M. M., \& Silveira, M. P. T. (2019). Análise de erros de prescrição em hospital do sul do Brasil. Revista Brasileira de Farmácia Hospitalar e Serviços de Saúde, 6(3), 23-26.

Lima, J. F. M. (2013). Efeito da incorporação de agentes antimicrobianos sobre propriedades físicas de materiais resilientes temporários para base de prótese. Dissertação, Mestrado em Ciências Odontológicas Aplicadas, Bauru.

Lima, T. A. M., Furini, A. A. C., Atique, T. S. C., Done, P. D., Machado, R. L. D., \& Godoy, M. F. (2016a). Análise de potenciais interações medicamentosas e reações adversas a anti-inflamatórios não esteroides em idosos. Revista Brasileira de Geriatria e Gerontologia, 19(3), 533-544.

Lima, T. A. M., Gouveia, M. I. S., Pereira, L. L. V., \& Godoy, M. F. (2016b). Erros de prescrições médicas em drogaria. Revista Infarma: Ciências Farmacêuticas, 28(1), 16-21.

Lins, B. G., Cazzamalli, F., \& Zancanaro, V. (2012). Análises de erros nas prescrições médicas de uma unidade básica de saúde de um município do meio oeste catarinense. Revista Interdisciplinar de Estudos em Saúde, 1(2), 62-77. 
Research, Society and Development, v. 10, n. 15, e485101522494, 2021

(CC BY 4.0) | ISSN 2525-3409 | DOI: http://dx.doi.org/10.33448/rsd-v10i15.22494

Lisboa, S. S. M. L. (2015). Análise farmacológica e legal de prescrições odontológicas de antibióticos: um estudo transversal. Tese de Doutorado em Odontologia, Universidade Federal de Minas Gerais, Belo Horizonte.

Loureiro, R. J., Roque, F., Rodrigues, A. T., Herdeiro, M. T., \& Ramalheira, E. (2016). O uso de antibióticos e as resistências bacterianas: breves notas sobre a sua evolução. Revista Portuguesa de Saúde Pública, 34(1), 77-84.

Marmitt, G. F. (2010). Prescrição de medicamentos para tratamento da dor por cirurgiões-dentistas vinculados a uma faculdade de odontologia. Trabalho de Conclusão de Curso de Graduação em odontologia, Universidade Federal do Rio Grande do Sul, Porto Alegre.

Melo, V. V., Duarte, I. P., \& Soares, A. Q. (2012). Guia de antimicrobianos. HC-UFG.

Milani, C. L., Kolodziejwski, W. T., Godoy, I. P., Salha, R. A. R., Remor, F., \& Nardi, A. (2017). Cuidados no tratamento odontológico em pacientes anticoagulados. Ação Odonto, (1), 10.

Moore, R. A., Derry, S., \& McQuay, H. J. (2007). Cyclo-oxygenase-2 selective inhibitors and nonsteroidal anti-inflammatory drugs: balancing gastrointestinal and cardiovascular risk. Bio Med Center Musculoskeletal Disorders, 8(73), 1-11.

Secoli, S. R. Interações medicamentosas: fundamentos para a pratica clínica da enfermagem. (2001). Revista da escola de farmácia da USP, 35(1), 28-34.

Souza, G. F. M., Silva, K. F. F. B., \& Brito, A. R. M. (2011). Prescrição medicamentosa em odontologia: normas e condutas. Cadernos Saúde Coletiva, 19(2), 208-214.

Vicente, A., Loffi, A. O. B., \& Nesi, H. (2013). Uso de corticosteroide no pré-operatório em cirurgia de terceiros molares. Revista Brasileira de Odontologia, $70(1), 22-27$

Walter, I. T. (2019). Avaliação do perfil de prescrição da associação de codeina e paracetamol na atenção básica à saúde em um municipio catarinense. Trabalho de Conclusão de Curso de Farmácia. Universidade Federal de Santa Catarina, Florianópolis.

Whalen, K., Finkel, R., \& Panavelil, T. A. (2016). Farmacologia ilustrada. (6a. ed.). Artmed. 